\title{
Numerical and Theoretical Analysis of Free Vibration of a Multi- Cracked Cantilever Beam with Rectangular Cross Section
}

\author{
Cem Boga \\ Adana Alparslan Turkes Science and Technology University, Faculty of Engineering, \\ Mechanical Engineering, PO box 01250, Adana, Turkey \\ E-mail: cboga@adanabtu.edu.tr
}

\begin{abstract}
Structures used in the application must perform their duties undamaged during the time they are used. Cracks often affect the dynamic properties of the structural elements and can cause severe durability problems. The crack detection in the structural elements and vibration analysis are vital in engineering applications and so far has been the subject of many researches. In present study, free vibration analysis of the un-cracked and cracked cantilever beam was performed and the first three natural frequencies were determined as theoretically and numerically. After verifying the results, the beams were modeled using CATIA software and analyzed using the finite element method with ANSYS software in order to get quick results. The effect of the location of the crack, the depth of the crack, the width of the crack and the number of cracks on the first three natural frequencies was investigated by performing a parametric study. The results are given in tables and graphs.
\end{abstract}

Keywords: Free vibration, cantilever beam, multi cracked, natural frequencies, mode shapes

DOI: $10.7176 / \mathrm{JSTR} / 5-3-20$

\section{Introduction}

Structures like beams are widely used in the steel construction of stadiums, bridges, buildings, skyscrapers, ships and many machines. There are few examples of real life systems which can be approximated to cantilever beam. For example, an aircraft wing, a tower crane overhang is like a cantilever beam. Such structures must perform their duties safely and without damage during their use. The most common type of damage in such beams is cracked structures. Beam cracks become more dangerous if there are static or dynamic loads. The presence of cracks in a single beam can cause failure the whole structure. Therefore, crack detection has an important role in engineering applications. In the literature, the subject of free vibration analysis of cracked beams has significantly increased in recent years. But, many of these studies have experimentally and numerically examined the effect of crack depth and crack location on the first three natural frequencies in single or two cracked beams. Patil and Verma [1] applied ANSYS software on both crack and un-crack cantilever beam for finite element analysis. The experiments have done for finding natural frequencies by using various cross section, crack location and crack depth. The consequences achieved from fuzzy logic technique and finite element analysis is compared by them. Orhan [2] performed the free and forced vibration analysis of the cantilever beam with one and double cracks. Natural frequencies are found by doing free vibration analysis in his study. In the investigation of crack analysis, change in natural frequencies and harmonic responses are evaluated related to the change in crack depth and location. Chaudhari and Patil [3] used crack and un-crack aluminum beam for finding first three natural frequencies. They obtained deflection and natural frequencies for the variety of beam condition at different crack depth and locations. Patil et al. [4] investigated the effect of vibration on I section steel cantilever beam using ANSYS Workbench R14.5. They carried out vibration analysis on beam without crack and with crack by using computer aided software ANSYS. Satpute et al. [5] did finite element analysis of cracked and uncracked cantilever circular beam using ANSYS 14.5 and obtained first three natural frequencies in concept Page | 177

www.iiste.org 
of transverse mode. They examined the effect of the location and depth of the crack on natural frequencies. In experimental frame, Barad et al. [6] found first two natural frequencies of the cracked cantilever beam. They presented the influence of the crack depth and location on natural frequencies. Gowd et al. [7] found first three relative natural frequencies for an un-cracked and single cracked beam with using finite element method and used two algorithms using fuzzy logic and artificial neural networks for crack detection. They used the first three relative natural frequencies as three inputs and the corresponding relative crack depth and location as the two outputs in the algorithms. Behera et al. [8] fulfilled numerical and experimental studies for finding mode shapes and natural frequencies of crack and healthy aluminium beam structure. They used fuzzy logic methodology for analysing the presence of a crack. Chaudhari and Patil [9] used fuzzy logic applications for identifying the fault in terms of crack in their investigation. They took into account the transverse surface of the crack. They made analysis by using finite element methods and fuzzy logic techniques. Sahu et al. [10] proposed a method like Fuzzy logic technique and Adaptive Genetic Algorithm for structural damage detection in an unhealthy cantilever aluminum alloy beam. Afterwards, the results obtained both from the experimental analysis and the proposed methods are verified. Parhi and Choudhury [11] investigated the crack on the horizontal surface using fuzzy logic technique and finite element methods. They used first three natural frequencies for input parameters to the fuzzy controller and the relative crack depth and location for output parameters of the fuzzy controller. Pawar and Sawant [12] used ANSYS software and developed an experimental setup for vibrational analysis of cracked cantilever beam. They compared and verified results of numerical and experimental analysis. Lal and Johny [13] fulfilled a parametric study to assess the effect of crack depth ratio, location of cracks and number of cracks on the first three natural frequencies of the isotropic cantilever beam. Agarwalla and Parhi [14] studied the effect of an open crack on free vibration of the cantilever beam and compared the results obtained from the numerical and the experimental method. Al-Ansari et al. [15] found the natural frequency of an unhealthy simple supported beam (the crack with different depths) analytically, experimentally and numerically by ANSYS program in their research. The results obtained from three methods are compared. A continuous bilinear model for the displacement field is used by Heydari et al. [16], for the investigation of forced flexural vibration of an unhealthy beam in their studies. In order to show the accuracy of the method, they compared the obtained frequency values and the finite element results. Mia et al. [17] found natural frequency and mode shapes of vibration for both healthy and unhealthy fixed-free beam. Using Finite Element Analysis software (Abaqus) for cracked beam, they analyzed for different crack depth and location.

In this study, the first three natural frequencies and mode shapes of an un-cracked and cracked cantilever beam with free vibration have been studied in details theoretically and using Finite Element Method (ANSYS). In addition, the first three natural frequencies of cantilever beam with single crack were obtained theoretically and numerically, then were compared with the literature and were observed to be quite compatible. For cracked cantilever beam four criteria such as different width of crack, different crack number, different crack location and different crack depth have been investigated. The effects of these criteria on the first three natural frequencies are shown by tables and graphs.

\section{Theory of Free Vibration for Un-cracked and Cracked Cantilever Beam}

The governing differential equation of motion for the free vibration of elastic beams is the equation given below in [18]:

$E I \frac{\partial^{4} y}{\partial x^{4}}+m \frac{\partial^{2} y}{\partial t^{2}}=0$

where $E$ is the elasticity modulus, $m$ is the beam mass, $I$ is the moment of inertia (for rectangular cross section,

$\left.I=\frac{b h^{3}}{12}\right), b$ is the beam width and $h$ is the beam height, $L$ is the length in Fig. 1.

Page | 178

WwW.iiste.org 
International Journal of Scientific and Technological Research

ISSN 2422-8702 (Online), DOI: 10.7176/JSTR/5-3-20

Vol.5, No.3, 2019

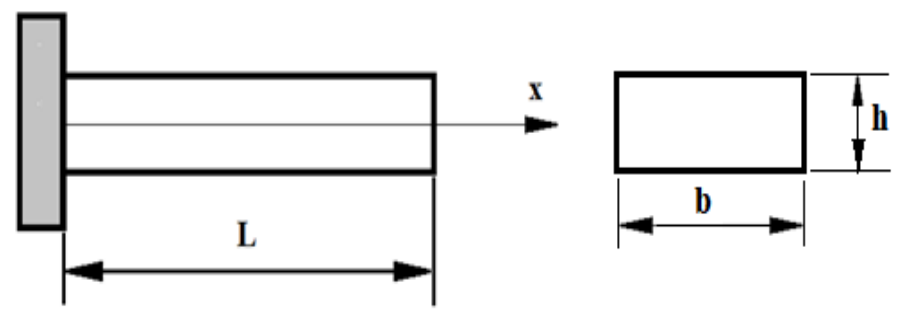

Figure 1. Un-cracked fixed-free beam and cross section

the solution $y(x, t)$ of Eq. (1) is given as follows:

$y(x, t)=Y(x) f(t)$

In Eq. (2) function $Y(x)$ that varies only with $x$, and a function $f(t)$ that varies only with time $(t)$.

By substituting Eq. (2) into Eq. (1) and is found;

$E I \frac{\partial^{4} Y(x) f(t)}{\partial x^{4}}=-m \frac{\partial^{2} Y(x) f(t)}{\partial t^{2}}$

$\frac{E I}{m} \frac{\partial^{4} Y(x) / \partial x^{4}}{Y(x)}=-\frac{\partial^{2} f(t) / \partial t^{2}}{f(t)}$

If each side of the Eq. ( $3 b$ ) is equal to the same constant $\omega^{2}$, that is;

$\frac{E I}{m} \frac{\partial^{4} Y(x) / \partial x^{4}}{Y(x)}=\omega^{2}$

$-\frac{\frac{\partial^{2} f(t)}{\partial t^{2}}}{f(t)}=\omega^{2}$

or

$\frac{\partial^{4} Y(x)}{\partial x^{4}}-\lambda^{4} Y(x)=0$

Page | 179

www.iiste.org 
$\frac{\partial^{2} f(t)}{\partial t^{2}}+\omega^{2} f(t)=0$

where

$\lambda^{4}=\frac{m \omega^{2}}{E I}$

The solution $Y(x)$ of Eq. (5a) may be assumed as

$Y(x)=C e^{\psi x}$

where $C$ and $\psi$ are constants. If the substitute Eq. (7) into Eq. (5a), it is obtained Eq. (8)

$\frac{\partial^{4} C e^{\psi x}}{\partial x^{4}}-\lambda^{4} C e^{\psi x}=0$

after mathematical operations, is obtain as follows:

$\psi^{4}=\lambda^{4}$

the roots of $\psi$ are as follows:

$\psi_{1}=\lambda, \psi_{2}=-\lambda, \psi_{3}=i \lambda, \psi_{4}=-i \lambda$,

In Eq. (9b), $i=\sqrt{-1}$. By using the roots of $\psi$ given by Eq. (9b), it is found that Eq. (7) may be written as

$Y(x)=C_{1} e^{\lambda x}+C_{2} e^{-\lambda x}+C_{3} e^{i \lambda x}+C_{4} e^{i \lambda x}$

By using the Eulerian relations

$e^{ \pm \lambda x}=\cosh \lambda x \pm \sinh \lambda x$

$e^{ \pm i \lambda x}=\cos \lambda x \pm i \sin \lambda x$

the trigonometric form of Eq. (10) is obtained:

$Y(x)=A_{1} \cosh \lambda x+A_{2} \sinh \lambda x+A_{3} \cos \lambda x+A_{4} \sin \lambda x$

Eq. (12) is the general solution of Eq. (5a). $A_{1}, A_{2}, A_{3}$ and $A_{4}$ and the values of $\lambda$ may be determined by using Eq. (12) and applying the beam's boundary conditions. From Eq. (6), it is obtained the frequencies $\omega$ $(\mathrm{rad} / \mathrm{sec})$, may be determined as follow [18]:

Page | 180

www.iiste.org 
$\omega=\lambda^{2} \sqrt{\frac{E I}{m}}$

If boundary conditions are written according to Fig. 1,

at $x=0, Y=0, \quad \frac{d Y}{d x}=0$

at $x=L, \quad \frac{d^{2} Y}{d x^{2}}=0, \quad \frac{d^{3} Y}{d x^{3}}=0$

If Eq. (14) and Eq. (15) is solved by applying boundary conditions, it is obtained Eq. (16) as

$\cosh \lambda L \cos \lambda L=-1$

Eq. (16) must be solved numerically and the graph of this equation is shown in Fig. 2 and the roots are shown Table 1.

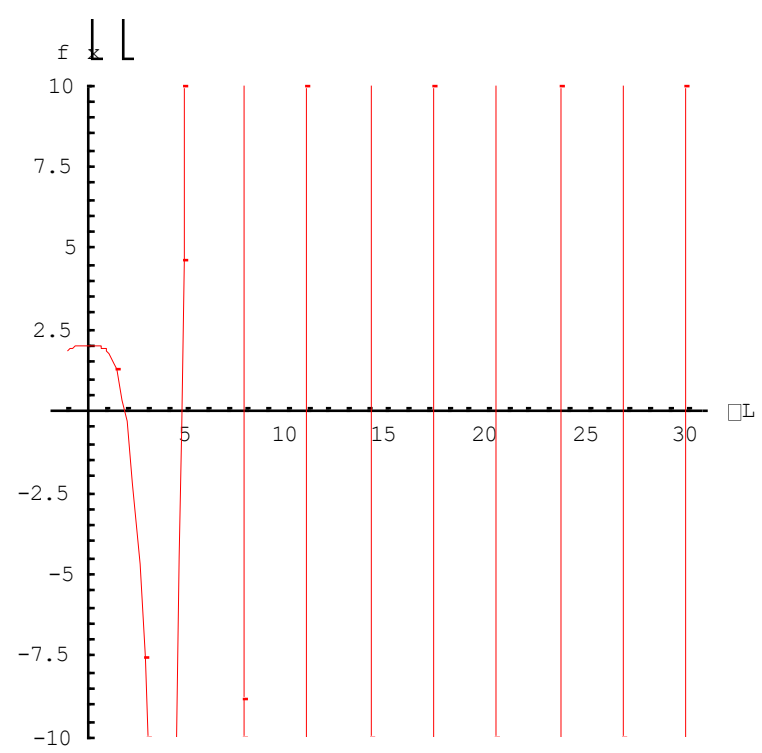

Figure 2. A graph of Eq. (16)

Table 1. The roots of Eq. (16)

\begin{tabular}{|l|c|}
\hline Index & $\lambda_{n} L$ \\
\hline $\mathrm{n}=1$ & 1.8751 \\
\hline $\mathrm{n}=2$ & 4.69409 \\
\hline $\mathrm{n}=3$ & 7.85476 \\
\hline $\mathrm{n}=4$ & 10.9955 \\
\hline
\end{tabular}

Page | 181 www.iiste.org 
The final equation for natural frequency of the $n$th mode $\left(\omega_{n}\right)$ of un-cracked beams is presented in Eq. (17). $\rho$ is the beam density and $A$ is the beam cross section area.

$\omega_{n}=\left(\lambda_{n} L\right)^{2} \sqrt{\frac{E I}{m}}=\left(\lambda_{n}\right)^{2} \sqrt{\frac{E I}{\rho A L^{4}}}$
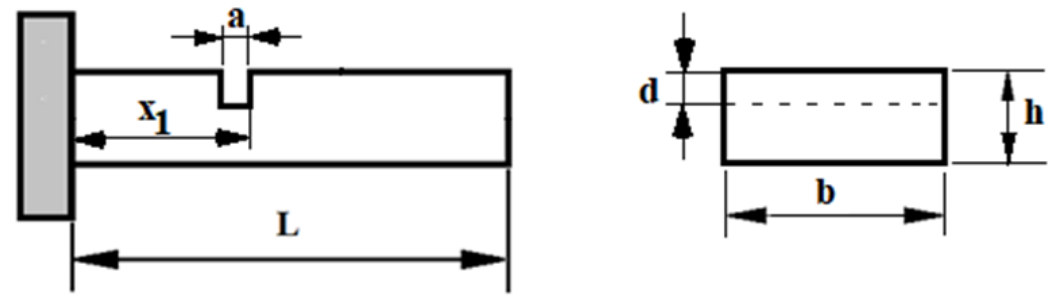

Figure. 3 Fixed-free beam with one crack

The equation below (Eq. 18) is natural frequency of the $n$th mode $\left(\omega_{n c}\right)$ for one cracked beams;

$\omega_{n c}=\left(\lambda_{n}\right)^{2} \sqrt{\frac{E I_{1}}{\rho A L^{4}}}$

$I_{1}=I-I_{c}$

where $I_{1}$ is the moment of inertia of a cracked beam, $I$ is the moment of inertia of a un-cracked beam and $I_{c}$ is the moment of inertia of cracked beam element $\left(I_{c}=\frac{b(h-d)^{3}}{12}\right), a$ is the crack width, $d$ is the crack depth, $x_{1}$ is the crack location from the fixed end. Whereas in this paper, in the free vibration analysis of multiple cracked beams, the parametric work was done numerically since it would be obtained faster with finite element methods instead of analytical methods.

\section{Verification of the Results}

For verification of the present exact results, an isotropic cantilever beam of dimensions $800 \mathrm{~mm} \times 20 \mathrm{~mm} \times$ $20 \mathrm{~mm}$, with single crack was considered. The other properties are as follows: the modulus of elasticity $E=$ $2.1 \times 10^{11} \mathrm{~N} / \mathrm{m}^{2}, \rho=7800 \mathrm{~kg} / \mathrm{m}^{3}$, poisons ratio $v=0.35$, crack width $a=1 \mathrm{~mm}$, crack depth $d=2 \mathrm{~mm}$ and for single crack location at $x_{1}=120 \mathrm{~mm}$ from the fixed end. The geometric model of beam was also modelled on CATIA software, the analysis was carried out in ANSYS and first three natural frequencies were extracted, the results of which are presented in Table 2. The results obtained from numerical analysis (ANSYS) were found to be in perfect agreement with the exact solution and results in the literature [19].

Page | 182

www.iiste.org 
Table 2. Comparision of modal frequencies of beam with

\begin{tabular}{|l|l|l|l|}
\hline \multicolumn{1}{|l|}{ single crack } \\
$\begin{array}{l}\text { Exact } \\
(\text { Present }) \\
(\mathrm{Hz})\end{array}$ & $\begin{array}{l}\text { ANSYS } \\
(\text { Present }) \\
(\mathrm{Hz})\end{array}$ & $\begin{array}{l}\text { Numerical } \\
(\text { Literature }) \\
(\mathrm{Hz})[19]\end{array}$ \\
\hline Mode 1 & 26.180 & 26.139 & 26.123 \\
\hline Mode 2 & 164.073 & 163.82 & 164.092 \\
\hline Mode 3 & 459.410 & 456.74 & 459.603 \\
\hline
\end{tabular}

\section{Parametric studies of multi-crack beams}

A parametric study was performed to determine the influence of crack width, crack numbers, crack location and crack depth on the first three natural frequencies of the cantilever beam. For this purpose, firstly the geometry was modelled on CATIA software each beam (Fig. 4). After that, the analysis was done in ANSYS (Fig. 5) and the results were obtained and presented with tables (Table 3-5) and graphs (Fig. 6-11). The frequency ratio $(f r)$ in the graphs is the ratio of the natural frequency of the cracked beam $(c n)$ to the natural frequency of the un-cracked beam (ucn) ( $f r=c n / u c n)$. An isotropic cantilever beam was considered with the following properties: length $L=800 \mathrm{~mm}$ with a rectangular cross-section with width $b=30 \mathrm{~mm}$ and height $h$ $=30 \mathrm{~mm}, E=2.1 \times 10^{11} \mathrm{~N} / \mathrm{m}^{2}, \rho=7850 \mathrm{~kg} / \mathrm{m}^{3}$ and $v=0.3$.

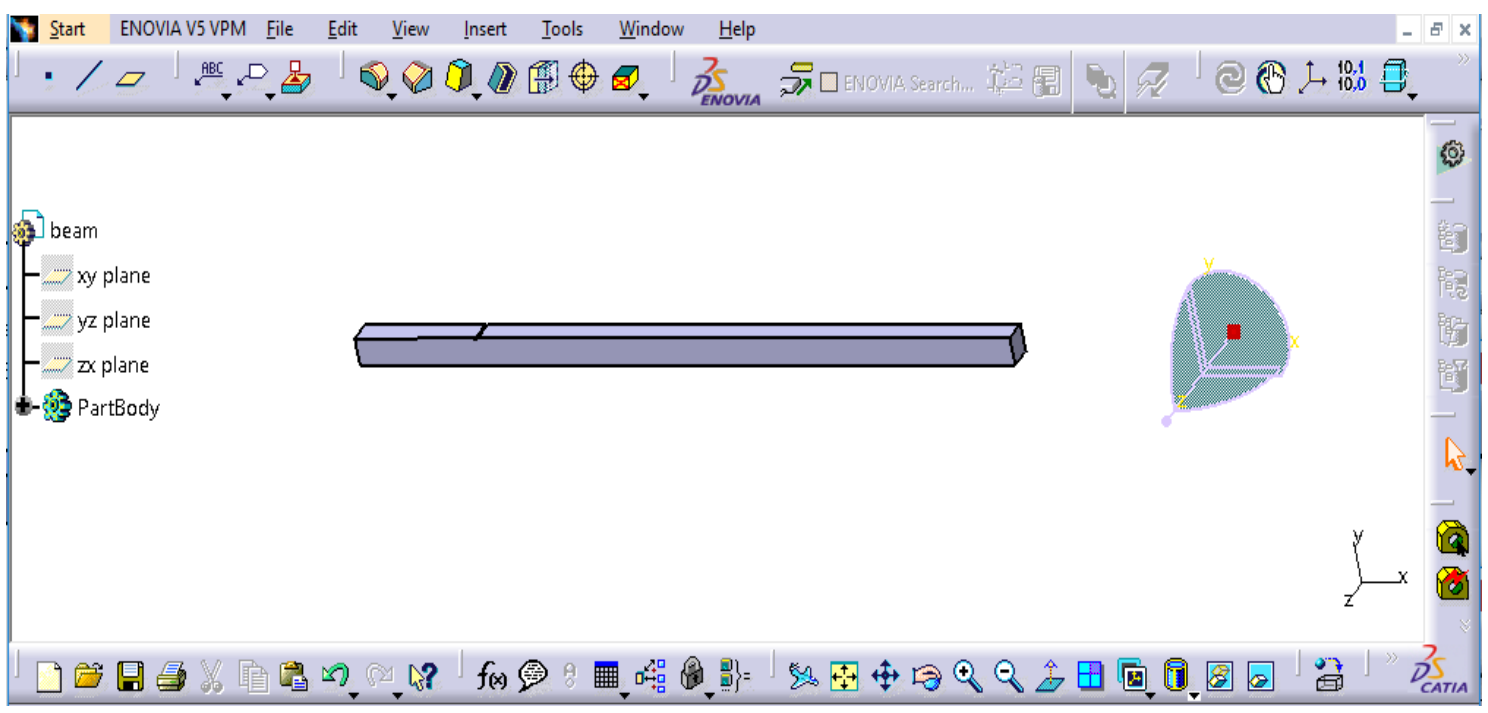

Figure 4. CATIA model of cantilever beam 


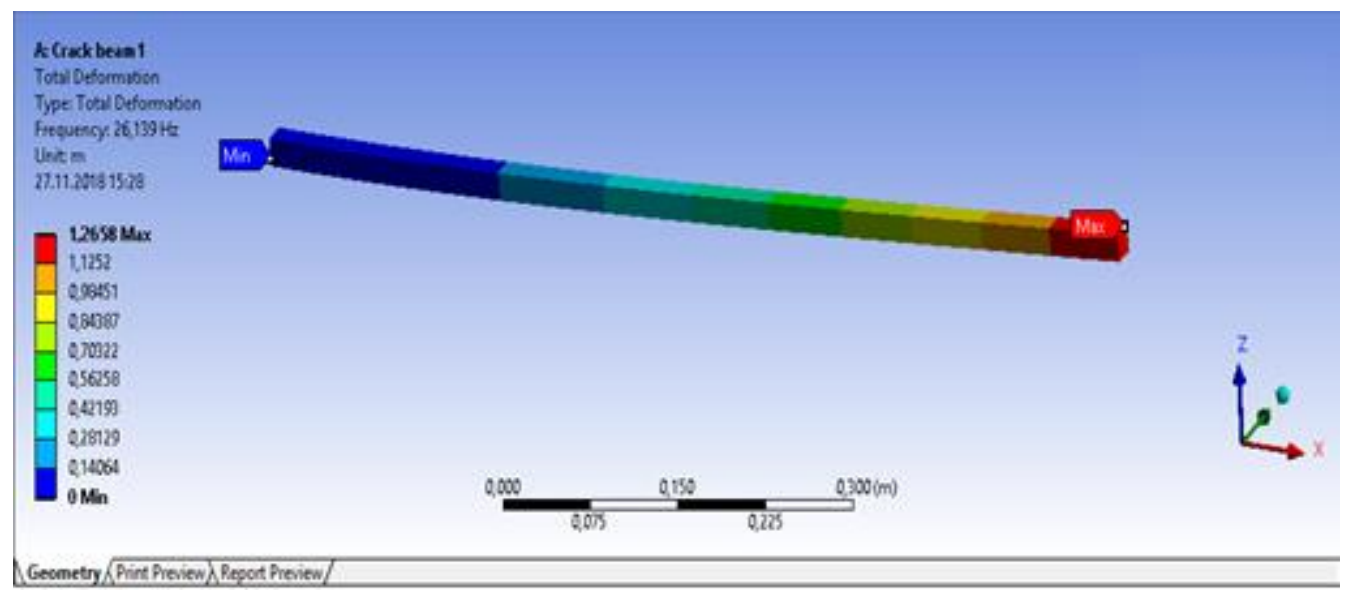

(a) $1^{\text {st }}$ Mode of vibration (single cracked beam)

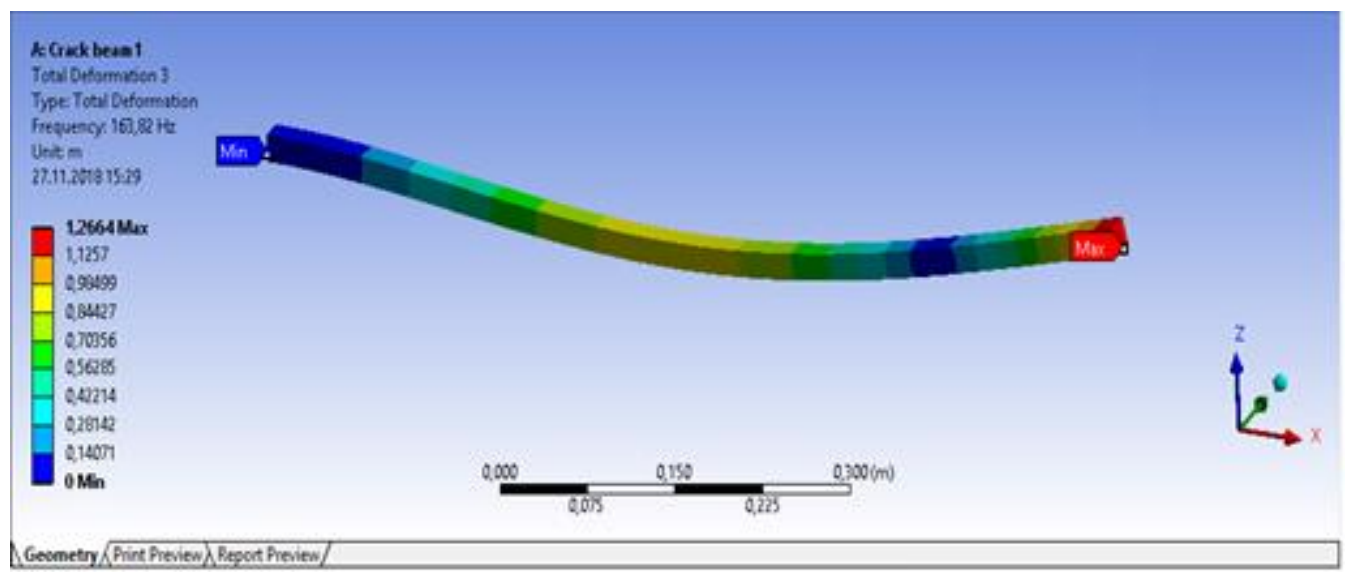

(b) $2^{\text {nd }}$ Mode of vibration (single cracked beam)

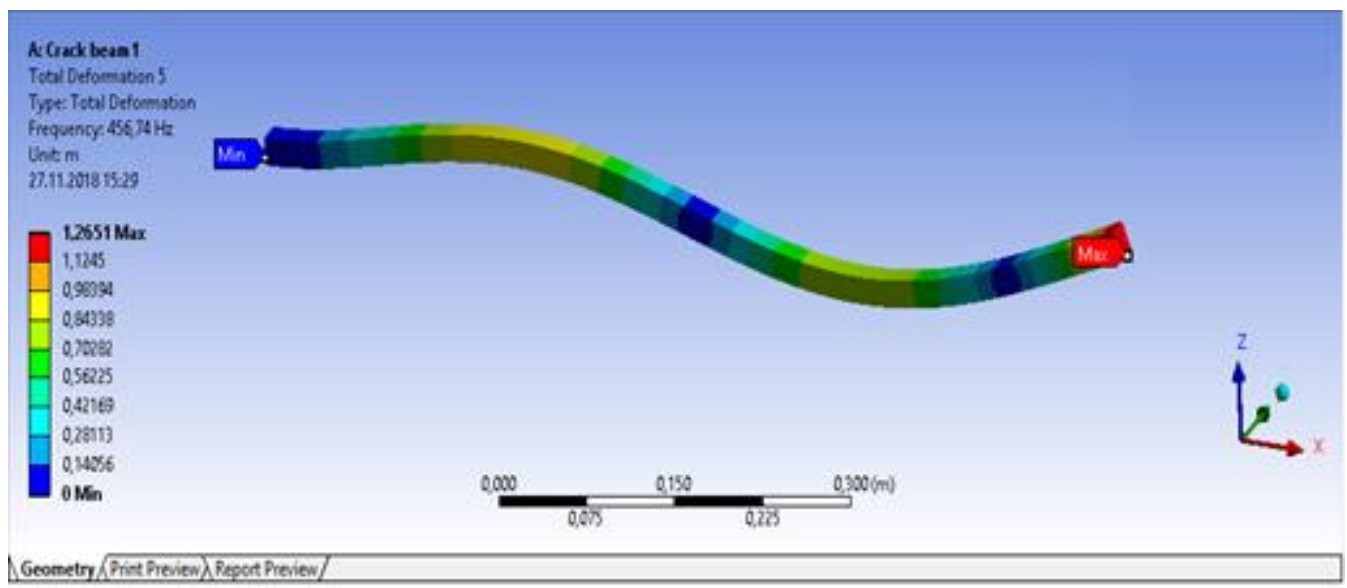

(c) $3^{\text {rd }}$ Mode of vibration (single cracked beam)

Figure 5. Mode shapes of first three natural frequencies of beam with single crack 
International Journal of Scientific and Technological Research ISSN 2422-8702 (Online), DOI: 10.7176/JSTR/5-3-20

Vol.5, No.3, 2019

Table 3. Natural frequencies of the cantilever beam with a crack for the first mode $(\mathrm{Hz}) \quad(a=1 \mathrm{~mm})$

\begin{tabular}{|c|c|c|c|c|c|c|}
\hline & Un-crack beam & $x_{1}=150$ & $x_{1}=300$ & $x_{1}=450$ & $x_{1}=600$ & $x_{1}=750$ \\
\hline$d=0.5 \mathrm{~mm}$ & \multirow{10}{*}{39.198} & 39.190 & 39.194 & 39.197 & 39.198 & 39.199 \\
\hline$d=1 \mathrm{~mm}$ & & 39.173 & 39.187 & 39.195 & 39.198 & 39.200 \\
\hline$d=1.5 \mathrm{~mm}$ & & 39.148 & 39.175 & 39.192 & 39.199 & 39.202 \\
\hline$d=2 \mathrm{~mm}$ & & 39.114 & 39.161 & 39.187 & 39.199 & 39.203 \\
\hline$d=2.5 \mathrm{~mm}$ & & 39.067 & 39.140 & 39.182 & 39.199 & 39.204 \\
\hline$d=3 \mathrm{~mm}$ & & 39.017 & 39.117 & 39.175 & 39.199 & 39.206 \\
\hline$d=3.5 \mathrm{~mm}$ & & 38.958 & 39.091 & 39.167 & 39.198 & 39.207 \\
\hline$d=4 \mathrm{~mm}$ & & 38.891 & 39.061 & 39.159 & 39.198 & 39.208 \\
\hline$d=4.5 \mathrm{~mm}$ & & 38.815 & 39.027 & 39.149 & 39.197 & 39.210 \\
\hline$d=5 \mathrm{~mm}$ & & 38.732 & 38.989 & 39.137 & 39.196 & 39.211 \\
\hline
\end{tabular}

Table 4. Natural frequencies of the cantilever beam with a crack for the second mode $(\mathrm{Hz})(a=1 \mathrm{~mm})$

\begin{tabular}{|c|c|c|c|c|c|c|}
\hline & Un-crack beam & $x_{1}=150$ & $x_{1}=300$ & $x_{1}=450$ & $x_{1}=600$ & $x_{1}=750$ \\
\hline$d=0.5 \mathrm{~mm}$ & \multirow{10}{*}{244.050} & 244.050 & 244.030 & 244.010 & 244.040 & 244.060 \\
\hline$d=1 \mathrm{~mm}$ & & 244.050 & 243.980 & 243.920 & 244.010 & 244.060 \\
\hline$d=1.5 \mathrm{~mm}$ & & 244.050 & 243.910 & 243.780 & 243.960 & 244.070 \\
\hline$d=2 \mathrm{~mm}$ & & 244.040 & 243.810 & 243.600 & 243.890 & 244.070 \\
\hline$d=2.5 \mathrm{~mm}$ & & 244.030 & 243.670 & 243.340 & 243.800 & 244.070 \\
\hline$d=3 \mathrm{~mm}$ & & 244.020 & 243.510 & 243.050 & 243.700 & 244.080 \\
\hline$d=3.5 \mathrm{~mm}$ & & 244.010 & 243.320 & 242.720 & 243.580 & 244.080 \\
\hline$d=4 \mathrm{~mm}$ & & 244.000 & 243.110 & 242.340 & 243.450 & 244.090 \\
\hline$d=4.5 \mathrm{~mm}$ & & 243.990 & 242.880 & 241.920 & 243.300 & 244.090 \\
\hline$d=5 \mathrm{~mm}$ & & 243.970 & 242.620 & 241.450 & 243.130 & 244.090 \\
\hline
\end{tabular}

Table 5. Natural frequencies of the cantilever beam with a crack for the third mode $(H z)(a=1 \mathrm{~mm})$

\begin{tabular}{|c|c|c|c|c|c|c|}
\hline & Un-crack beam & $x_{1}=150$ & $x_{1}=300$ & $x_{1}=450$ & $x_{1}=600$ & $x_{1}=750$ \\
\hline$d=0.5 \mathrm{~mm}$ & \multirow{10}{*}{676.410} & 676.390 & 676.340 & 676.370 & 676.280 & 676.390 \\
\hline$d=1 \mathrm{~mm}$ & & 676.340 & 676.190 & 676.310 & 676.020 & 676.400 \\
\hline$d=1.5 \mathrm{~mm}$ & & 676.270 & 675.960 & 676.220 & 675.620 & 676.410 \\
\hline$d=2 \mathrm{~mm}$ & & 676.160 & 675.660 & 676.090 & 675.090 & 676.400 \\
\hline$d=2.5 \mathrm{~mm}$ & & 676.020 & 675.220 & 675.910 & 674.350 & 676.340 \\
\hline$d=3 \mathrm{~mm}$ & & 675.860 & 674.760 & 675.730 & 673.540 & 676.370 \\
\hline$d=3.5 \mathrm{~mm}$ & & 675.680 & 674.220 & 675.500 & 672.590 & 676.360 \\
\hline$d=4 \mathrm{~mm}$ & & 675.460 & 673.600 & 675.250 & 671.520 & 676.350 \\
\hline$d=4.5 \mathrm{~mm}$ & & 675.220 & 672.910 & 674.960 & 670.310 & 676.330 \\
\hline$d=5 \mathrm{~mm}$ & & 674.960 & 672.150 & 674.640 & 668.970 & 676.310 \\
\hline
\end{tabular}

Page | 185

WWw.iiste.org 


\section{Results and Discussion}

Some of the findings are presented below.

- As the crack depth increased, a decrease in all three natural frequencies was observed (Fig. 6 - Fig. 8).

- As the number of cracks increased, all three natural frequency values decreased (Table 6).

- As the crack width increased, a decrease was observed in the first natural frequency values and there was no significant decrease in the second and third natural frequencies (Table 7).

- As can be seen from Figure 6, when the crack is at a distance of about $750 \mathrm{~mm}$ from the fixed end, it is understood that the first natural frequency is least affected and the crack is greatly influenced when it is $150 \mathrm{~mm}$ away from the fixed end. It can easily be cleared by the fact that the actual bending moment in the immediate vicinity of the cantilever beam is the largest.

- As can be seen from Figure 7, it is understood that when the crack is seen right in the beam center, the second natural frequency is greatly influenced and the slightly influenced when the crack is located near the fixed end. The reason for such act is defined by the fact that the bending moment in the center of the beam is large.

- In Figure 8, rapid change is seen in the third natural frequency at a distance of about $600 \mathrm{~mm}$ from the fixed end and no change occurs in the natural frequency at the beam center. The reason for this is that the nodal point is located in the center for the third mode.

- It is understood from Figure 9 that the natural frequency is slightly influenced when the crack depth is $0.5 \mathrm{~mm}$, and is greatly influenced when it is $20 \mathrm{~mm}$.

- As seen in Figure 10, the second natural frequency is highly affected at the center of the crack and the depth is $5 \mathrm{~mm}$, and the least effect is for the crack depth of $0.5 \mathrm{~mm}$.

In Figure 11, it is clear that the third natural frequency no change occurs in the crack depth of $0.5 \mathrm{~mm}$.

Table 6. The effect of the number of cracks on the first three natural frequencies $(d=1.5 \mathrm{~mm}, a=2 \mathrm{~mm})$

\begin{tabular}{|l|l|l|l|}
\hline Crack number & First mode & Second mode & Third mode \\
\hline $1\left(x_{1}=150\right)$ & 39.138 & 244.050 & 676.260 \\
\hline $2\left(x_{2}=200\right)$ & 39.093 & 244.050 & 675.770 \\
\hline $3\left(x_{3}=250\right)$ & 39.059 & 243.990 & 675.120 \\
\hline $4\left(x_{4}=300\right)$ & 39.036 & 243.840 & 674.650 \\
\hline $5\left(x_{5}=350\right)$ & 39.019 & 243.620 & 674.490 \\
\hline $6\left(x_{6}=400\right)$ & 39.007 & 243.340 & 674.450 \\
\hline $7\left(x_{7}=450\right)$ & 39.001 & 243.050 & 674.250 \\
\hline $8\left(x_{8}=500\right)$ & 38.997 & 242.790 & 673.660 \\
\hline $9\left(x_{9}=550\right)$ & 38.999 & 242.600 & 672.820 \\
\hline $10\left(x_{10}=600\right)$ & 39.001 & 242.450 & 671.960 \\
\hline $11\left(x_{11}=650\right)$ & 39.010 & 242.370 & 671.390 \\
\hline
\end{tabular}

Page $\mid 186$

www.iiste.org 
International Journal of Scientific and Technological Research ISSN 2422-8702 (Online), DOI: 10.7176/JSTR/5-3-20

Vol.5, No.3, 2019

Table 7. The effect of the crack width on the first three natural

\begin{tabular}{|l|l|l|l|}
\multicolumn{5}{|c}{ frequencies $\left(x_{1}=150 \mathrm{~mm}, d=1.5 \mathrm{~mm}\right)$} \\
\hline$a(\mathrm{~mm})$ & First mode & Second mode & Third mode \\
\hline 1 & 39.148 & 244.050 & 676.270 \\
\hline 1.5 & 39.143 & 244.050 & 676.270 \\
\hline 2 & 39.138 & 244.050 & 676.260 \\
\hline 2.5 & 39.134 & 244.050 & 676.260 \\
\hline 3 & 39.129 & 244.050 & 676.270 \\
\hline
\end{tabular}

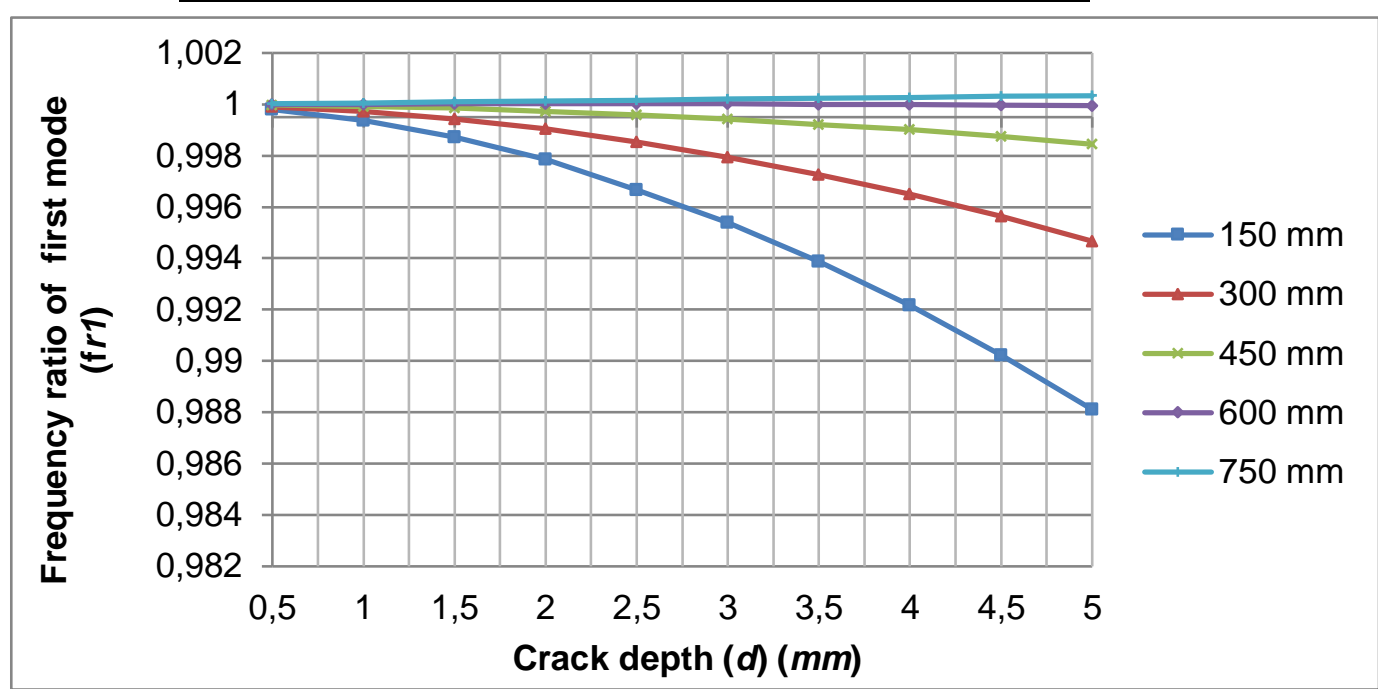

Figure 6. Variation of the first natural frequency ratio depending on the depth of the crack for the various crack locations

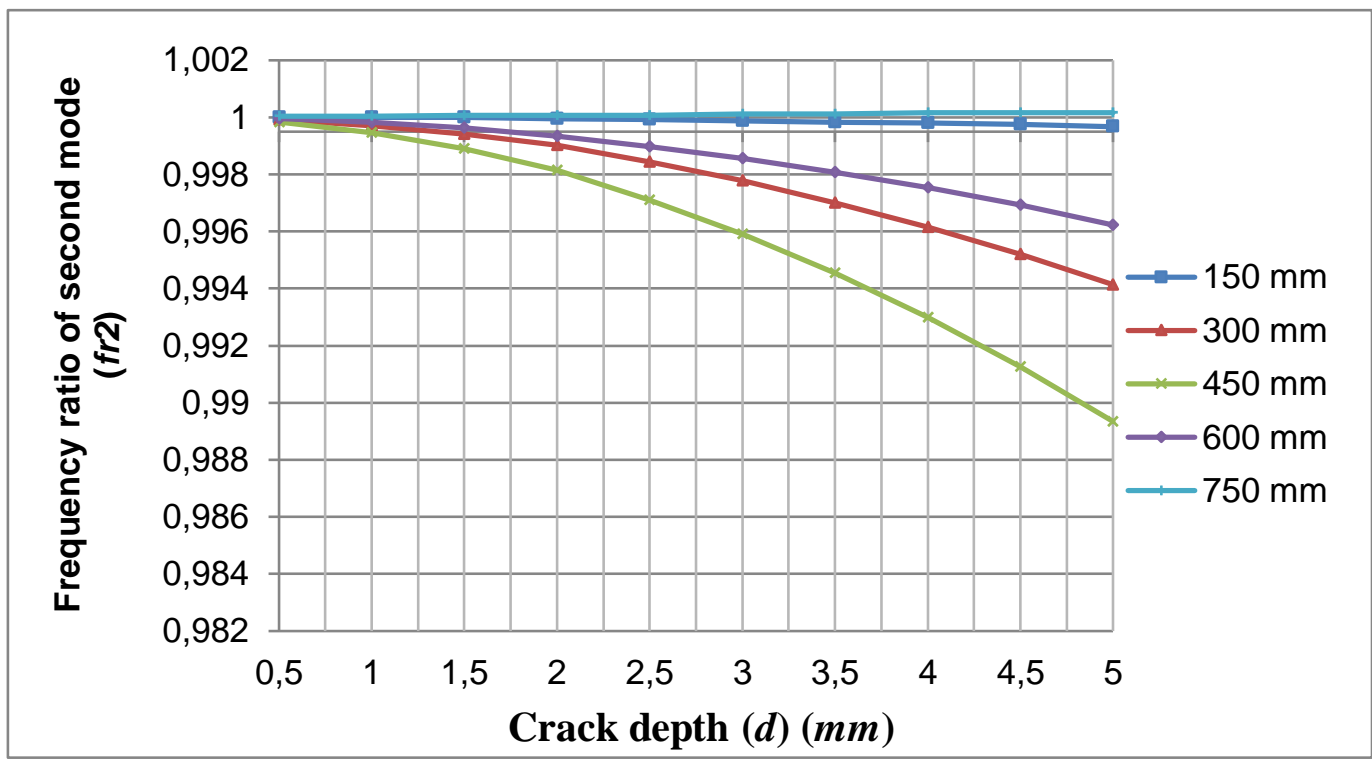

Figure 7. Variation of the second natural frequency ratio depending on the depth of the crack for the various crack locations 
International Journal of Scientific and Technological Research ISSN 2422-8702 (Online), DOI: 10.7176/JSTR/5-3-20

Vol.5, No.3, 2019

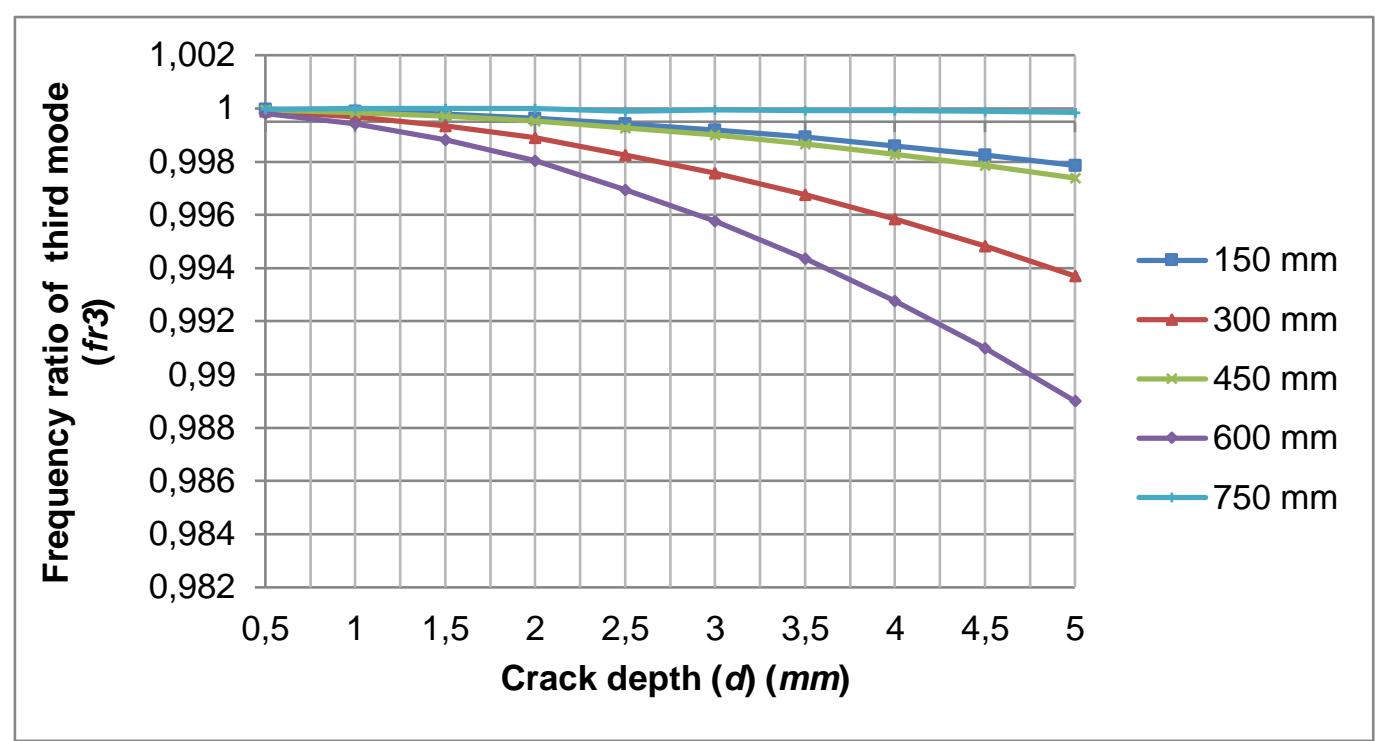

Figure 8. Variation of the third natural frequency ratio depending on the depth of the crack for the various crack locations

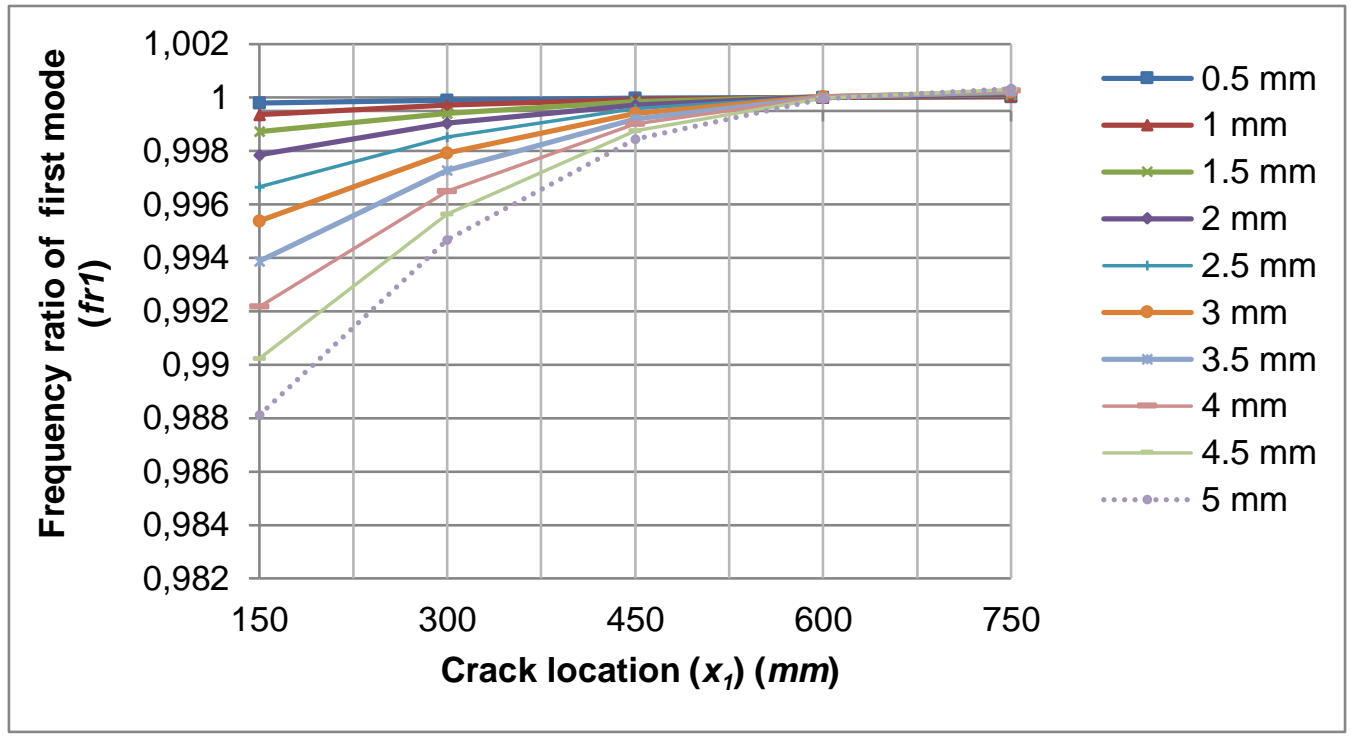

Figure 9. Variation of the first natural frequency ratio depending on the crack locations for the various crack depths 


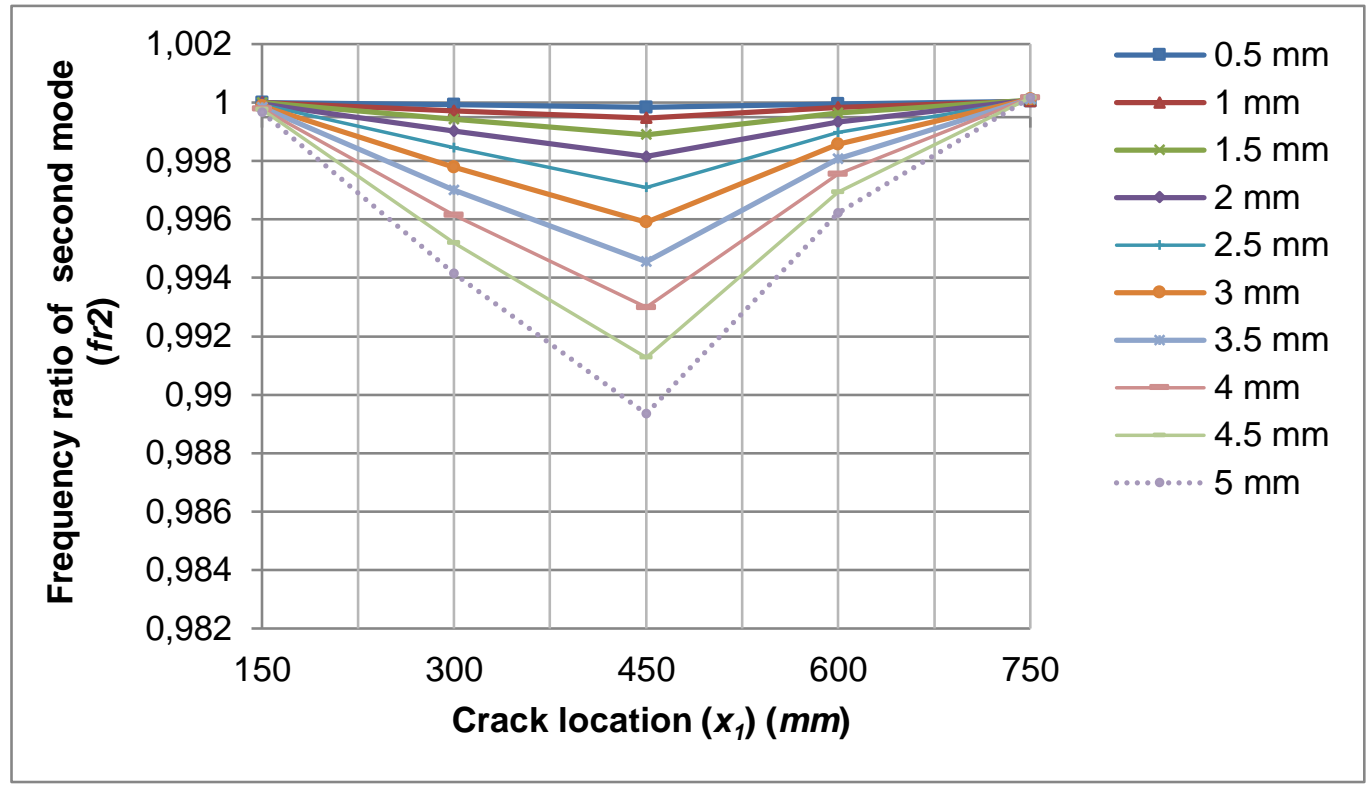

Figure 10. Variation of the second natural frequency ratio depending on the crack locations for the various crack depths

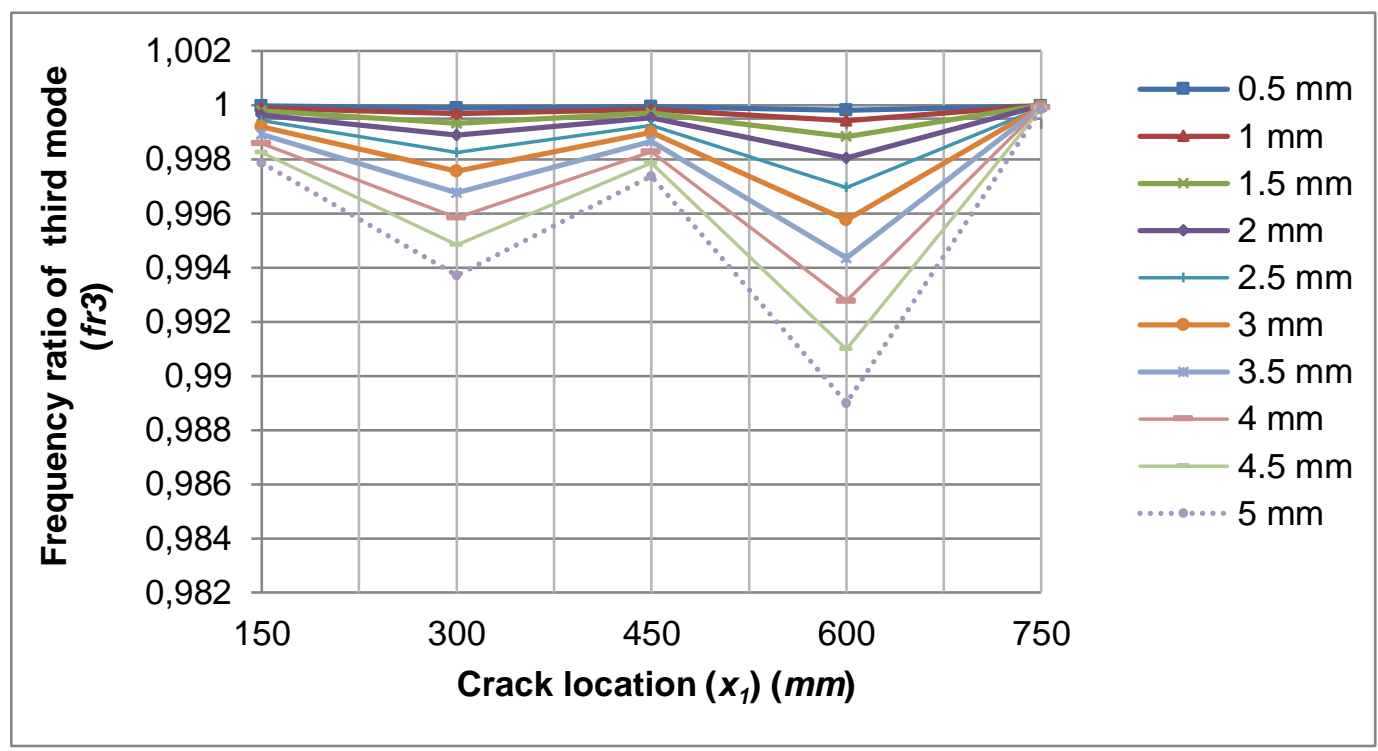

Figure 11. Variation of the third natural frequency ratio depending on the crack locations for the various crack depths

\section{Conclusions}

The effect of crack depth and location, crack width and number of cracks on natural frequencies was investigated as theoretical and numerical in this paper. The first three natural frequencies and mode shapes of an un-cracked and cracked cantilever beam with free vibration have been studied in details theoretically and using Finite Element Method (ANSYS), then were compared with the literature and were observed to be Page | 189 www.iiste.org 
International Journal of Scientific and Technological Research

ISSN 2422-8702 (Online), DOI: 10.7176/JSTR/5-3-20

Vol.5, No.3, 2019

quite compatible. As the crack depth and the number of cracks increased, a decrease in all three natural frequencies was observed. The effects of crack depth and location, crack width and number of cracks on the first three natural frequencies are shown by tables and graphs.

\section{References}

1. Patil, R.R., \& Verma, D. (2016) Free vibrational analysis of cracked and un-cracked cantilever beam. International Research Journal of Engineering and Technology (IRJET), 3(2):260-277.

2. Orhan, S. (2007) Analysis of free and forced vibration of a cracked cantilever beam. NDT\&E International, 40:443-450. doi:10.1016/j.ndteint.2007.01.010

3. Chaudhari, J.R., \& Patil, C.R. (2016) Study of static and modal analysis of un-crack and crack cantilever beam using FEA. International Journal of Engineering Research \& Technology (IJERT), 5(04):534-542.

4. Varsha, B.P., Lale, S.V., Pawar, Y.P., \& Pise, C.P. (2017) Vibration analysis of I section cantilever beam. International Journal Of Science, Engineering And Technology Research (IJSETR), 6(6):9961003.

5. Satpute, D., Baviskar, P., Gandhi, P., Chavanke, M., \& Aher, T. (2017) Crack detection in cantilever shaft beam using natural frequency. Materials Today: Proceedings, 4:1366-1374.

6. Barad, K.H., Sharma, D.S., \& Vyas, V. (2013) Crack detection in cantilever beam by frequency based method. Procedia Engineering, 51:770 - 775. doi: 10.1016/j.proeng.2013.01.110

7. Gowd, B.P., Jayasree, K., \& Hegde, M.N. (2018) Comparison of artificial neural networks and fuzzy logic approaches for crack detection in a beam like structure. International Journal of Artificial Intelligence and Applications (IJAIA), 9(1):35-51. doi:10.5121/ijaia.2018.9103

8. Behera, S.K., Parhi, D.R., \& Das, H.C. (2018) Numerical, experimental and fuzzy logic applications for investigation of crack location and crack depth estimation in a free-free aluminum beam. Vibrations in Physical Systems, 29:1-20.

9. Chaudhari, J.R., \& Patil, C.R. (2017) Fault diagnosis in cantilever beam using fuzzy logic. European Journal of Advances in Engineering and Technology, 4(5): 332-342.

10. Sahu, S., Kumar, P.B., \& Parhi, D.R. (2017) Design and development of 3-stage determination of damage location using Mamdani-Adaptive Genetic-Sugeno Model. Journal of Theoretical and Applied Mechanics, 55(4):1325-1339. doi:10.15632/jtam-pl.55.4.1325

Page $\mid 190$

www.iiste.org 
11. Parhi, D.R., \& Choudhury, S. (2011) Smart crack detection of a cracked cantilever beam using fuzzy logic technology with hybrid membership functions. Journal of Engineering and Technology Research, 3(8):270-278.

12. Pawar, R.S., \& Sawant, S.H. (2015) Vibrational analysis of cracked cantilever beam subjected to harmonic excitation with nonlinear parameters. International Journal of Science, Engineering and Technology Research (IJSETR), 4(12):4203-4209.

13. Lal, G., \& Johny, A. (2017) Vibration control of cantilever beam with multiple cracks. International Journal of Advances in Scientific Research and Engineering (ijasre), 3(4):76-85.

14. Agarwalla, D.K., \& Parhi, D.R. (2013) Effect of crack on modal parameters of a cantilever beam subjected to vibration. Procedia Engineering, 51:665-669. doi: 10.1016/j.proeng.2013.01.094

15. Al-Ansari LS, Al-Waily M, \& Al-Hajjar AMH (2012) Experimental and numerical study of crack effect on frequency of simple supported beam. Al-Khwarizmi Engineering Journal, 8(2):30-41.

16. Heydari, M., Ebrahimi, A., \& Behzad, M. (2014) Forced vibration analysis of a Timoshenko cracked beam using a continuous model for the crack. Engineering Science and Technology, an International Journal, 17:194-204. http://dx.doi.org/10.1016/j.jestch.2014.05.003

17. Mia, M.S., Islam, M.S., \& Ghosh, U. (2017) Modal analysis of cracked cantilever beam by finite element simulation. Procedia Engineering, 194:509-516. doi:10.1016/j.proeng.2017.08.178

18. Fertis, D.G. (1995) Mechanical and structural vibrations. John Wiley \& Sons, Inc., USA.

19. Shifrin, E.I., \& Ruotolo, R. (1999) Natural frequencies of a beam with an arbitrary number of cracks. Journal of Sound and Vibration, 222(3):409- 423. https://doi.org/10.1006/jsvi.1998.2083

20. Sutar, M.K., \& Pattnaik, S. (2010) Vibration characteristics of a cracked cantilever beam under free vibration. Noise \& Vibration Worldwide, 41(9):16-21. DOI:10.1260/0957-4565.41.9.16

Page | 191 www.iiste.org 